\title{
Socially Modulated Cell Proliferation Is Independent of Gonadal Steroid Hormones in the Brain of the Adult Green Treefrog (Hyla cinerea)
}

\author{
Lynn M. Almlia Walter Wilczynski ${ }^{b}$ \\ a Institute for Neuroscience, The University of Texas at Austin, Austin, Tex., and beuroscience Institute and \\ Center for Behavioral Neuroscience, Georgia State University, Atlanta, Ga., USA
}

\section{Key Words}

Amphibian - Cell proliferation - BrdU · Neurogenesis • Acoustic communication - Social behavior - Estrogen • Testosterone

\begin{abstract}
Gonadal steroid hormones have been shown to influence adult neurogenesis in addition to their well-defined role in regulating social behavior. Adult neurogenesis consists of several processes including cell proliferation, which can be studied via 5-bromo-2'-deoxyuridine (BrdU) labeling. In a previous study we found that social stimulation altered both cell proliferation and levels of circulating gonadal steroids, leaving the issue of cause/effect unclear. In this study, we sought to determine whether socially modulated BrdU-labeling depends on gonadal hormone changes. We investigated this using a gonadectomy-implant paradigm and by exposing male and female green treefrogs (Hyla cinerea) to their conspecific chorus or control stimuli (i.e. random tones). Our results indicate that socially modulated cell proliferation occurred independently of gonadal hormone levels; furthermore, neither androgens in males nor estrogen in females increased cell proliferation in the preoptic area (POA) and infundibular hypothalamus, brain regions involved in endo-
\end{abstract}

crine regulation and acoustic communication. In fact, elevated estrogen levels decreased cell proliferation in those brain regions in the implanted female. In male frogs, evoked calling behavior was positively correlated with BrdU-labeling in the POA; however, statistical analysis showed that this behavior did not mediate socially induced cell proliferation. These results show that the social modulation of cell proliferation can occur without gonadal hormone involvement in either male or female adult anuran amphibians, and confirms that it is independent of a behavioral response in males.

Copyright $\odot 2012$ S. Karger AG, Basel

\section{Introduction}

The relation between social behavior or social interactions and adult neurogenesis is an emerging field, reviewed by Gheusi et al. [2009], building on early discoveries relating social interactions to the plasticity of the adult brain [Rozenzweig and Bennett, 1977]. Neurogenesis consists of several processes including cell proliferation, differentiation, migration, and survival. These processes have been shown to be modulated by the reception of social stimuli in specialized nuclei related to signal produc-

\section{KARGER \\ Fax +4161306 1234 \\ E-Mail karger@karger.ch}

www.karger.com
(C) 2012 S. Karger AG, Basel

0006-8977/12/0793-0170\$38.00/0

Accessible online at:

www.karger.com/bbe
Lynn M. Almli

Psychiatry and Behavioral Sciences, Emory University

101 Woodruff Circle, Suite 4000

Atlanta, GA 30322 (USA)

Tel. +1 678671 7051, E-Mail lynn.almli@emory.edu 
tion in mammals [Smith et al., 2001; Fowler et al., 2002; Baudoin et al., 2005], birds [Lipkind et al., 2002; Barnea et al., 2006], fish [Dunlap et al., 2006, 2008, 2011], and crustaceans [Song et al., 2007].

Our previous study [Almli and Wilczynski, 2009] demonstrated that the number of proliferating cells, as labeled by 5-bromo-2'-deoxyuridine (BrdU) incorporation, can be modulated in adult animals in naturally cycling reproductive condition via acoustic social stimuli in a region- and sex-specific manner. In males, social stimulation increased proliferating cell numbers in the preoptic area (POA), whereas in females this increase occurred in the infundibular hypothalamus (IF). Interestingly, the POA and part of the IF [the ventral hypothalamus (VH)] are reproductive centers of the basal forebrain and show sexually dimorphic functions in vertebrates (the POA in males and the $\mathrm{VH}$ in females). Furthermore, they receive auditory information from thalamic and midbrain nuclei [Wilczynski et al., 1993; Emerson and Boyd, 1999; Wilczynski and Endepols, 2007], and contain neurons that respond to a conspecific chorus in anuran amphibians [Wilczynski and Allison, 1989; Allison, 1992].

Social stimulation also elevates circulating gonadal steroid levels (in frogs [Burmeister and Wilczynski, 2000; Chu and Wilczynski, 2001; Lynch and Wilczynski, 2006]). Often separately from social behavior, gonadal steroid hormones have been shown to affect the process of adult neurogenesis but their effects seem to be dependent on the species, region, and dose of the hormone [reviewed in Fowler et al., 2008; Galea, 2008]; in general, estrogens have been reported to affect both cell proliferation and survival, whereas androgens have been reported to mainly affect cell survival. Indeed, whether hormone changes were mediating the effects on cell proliferation in our previous study is unclear. Because social stimulation affects both gonadal steroid levels and cell proliferation in frogs, we could not determine with certainty if the hormone change mediated or influenced the increase in cell proliferation, or if they were two separate phenomena related to the stimulation. Although androgen changes co-occurred with increases in cell proliferation following exposure to conspecific calls, and therefore might have contributed to the social modulation of cell proliferation in males, estrogens did not seem to modulate socially induced cell proliferation in females [Almli and Wilczynski, 2009]. In this study, we sought to determine experimentally the role of gonadal steroid hormones in cell proliferation in general and specifically whether they are important for socially modulated cell proliferation. To address this question, we gonadectomized male and fe-

Socially Modulated Cell Proliferation in Hyla cinerea male Hyla cinerea; in half of the frogs, we replaced gonadal steroid hormones (testosterone in males and estrogen in females). We then exposed the gonadectomized and implanted frogs to a conspecific mating chorus or a control stimulus (random tones) and assessed the number of proliferating cells via BrdU-immunoreactivity.

Gonadal steroid hormones regulate social behaviors and ensure the appropriate timing of reproduction. In seasonally breeding anuran amphibians, gonadal hormones fluctuate seasonally in concert with reproductive social behavior. This occurs with androgens in males [Varriale et al., 1986; Itoh et al., 1990; Itoh and Ishii, 1990; Gobbetti et al., 1991; Polzonetti-Magni et al., 1998] and estrogen (among others) in females [Licht et al., 1983; Pierantoni et al., 1984; Iela et al., 1986]. Gonadal hormones and reproductive behavior also fluctuate within the breeding season of female anurans [Lea et al., 2000; Bosch and Boyero, 2004; Lynch and Wilczynski, 2005]. The reciprocal case is also evident, or in other words, reproductive or social behavior can influence gonadal hormone levels. In anurans, social cues produced by conspecifics can regulate gonadal hormone production [Burmeister and Wilczynski, 2000; Chu and Wilczynski, 2001; Lynch and Wilczynski, 2006].

Green treefrogs $(H$. cinerea) are highly social seasonal breeders [e.g. Gerhardt, 1988]. During the breeding season, male treefrogs gather nightly and call to attract females, forming a mating chorus. Calling is the major socio-sexual behavior expressed by males, whereas phonotaxic behavior in response to male calls is the main socio-sexual behavior expressed by females. Thus, social signals are almost solely acoustic in anuran amphibians. Calling behavior in male anurans is dependent on testosterone [Wada et al., 1976; Wada and Gorbman, 1977a; Wetzel and Kelley, 1983; Solis and Penna, 1997; Burmeister and Wilczynski, 2001] and eliminated upon castration [Schmidt, 1966; Palka and Gorbman, 1973; Kelley and Pfaff, 1976; Burmeister and Wilczynski, 2001]. The endocrine control of social behavior in females (i.e. phonotaxis), on the other hand, may involve multiple factors [for review, see Wilczynski et al., 2005; Gordon and Gerhardt, 2009]. However, studies suggest that estrogen [Lynch et al., 2006; Chakraborty and Burmeister, 2009; Wilczynski and Lynch, 2011], estrogen and progesterone [e.g. Kelley, 1982], or progesterone and prostaglandin [Gordon and Gerhardt, 2009] are necessary to promote phonotaxis in females.

The anuran amphibian central nervous system has unique qualities that facilitate the study of the social modulation of adult neurogenesis. For example, adult an- 
uran brains exhibit high levels of constitutive cell proliferation [Almli and Wilczynski, 2007; Simmons et al., 2008] and contain well-defined circuitries that control the expression of socio-sexual behavior [e.g. Wilczynski et al., 1993; Wilczynski and Ryan, 2010]. Further, neuroplasticity in the anuran socio-sexual system has been demonstrated via the social modulation of gonadotropinreleasing hormone $(\mathrm{GnRH})$ immunoreactive cell number [Burmeister and Wilczynski, 2005] and the proliferation of new brain cells [Almli and Wilczynski, 2009]. The green treefrog is thus an excellent model for studying the link between social behavior, gonadal steroids, and adult neurogenesis, specifically cell proliferation.

\section{Materials and Methods}

Experimental Animals

We purchased adult male and female green treefrogs $(H$. cinerea; snout-vent length range $46-53 \mathrm{~mm}$ ) from Charles Sullivan Co. (Nashville, Tenn., USA) and housed them in small groups (approx. 4-6) in an aquarium with water, plastic plants, and rocks. The treefrogs were fed crickets twice weekly and were provided water ad libitum. Environmental conditions included an ambient temperature of $23^{\circ} \mathrm{C}$ and a 14:10 light:dark cycle. All procedures were performed in accordance with a protocol approved by The University of Texas at Austin Institutional Animal Care and Use Committee.

\section{Hormone Manipulation and Surgical Procedures}

Blank and hormone implants were made in advance and soaked in $0.9 \%$ saline overnight before inserting into the frogs. Silastic $^{\odot}$ capsules $(1.47 \mathrm{~mm}$ i.d. $\times 1.96 \mathrm{~mm}$ o.d. $\times 6.5 \mathrm{~mm}$ length) were sealed empty (Blank; $n=15$ ) or filled with approximately $6 \mathrm{mg}$ of crystalline testosterone propionate (Sigma, St. Louis, Mo., USA) and sealed (Testosterone; $\mathrm{n}=15$ ). Due to extremely high estrogen levels produced from Silastic implants containing estrogen [Almli, unpubl. obs.], female frogs received implants of RTV silicone elastomer [6382 Factor II Inc., Lakeside, Ariz., USA; see Salek et al., 2001; Sisneros et al., 2004]. For estrogen-containing pellets (Estrogen; $\mathrm{n}=17$ ), $1 \mathrm{ml}$ of elastomer was mixed with approximately $5 \mathrm{mg}$ of 17- $\beta$-estradiol-3-benzoate (Fisher, Fair Lawn, N.J., USA), allowed to cure, and then formed into disks ( $3 \mathrm{~mm}$ diameter $\times 2.5 \mathrm{~mm}$ total length). The remaining females received same-sized pellets which contained silicone elastomer only (Blank; $\mathrm{n}=17$ ).

For gonadectomy and the implantation of blank capsules/ pellets or capsules/pellets containing sex steroid hormones, we first anesthetized the animals by immersion in $0.2 \%$ tricaine methanosulfate (MS-222; Sigma-Aldrich, Milwaukee, Wisc., USA). Males were castrated and females were ovariectomized by extracting the testes and ovaries, respectively, through a small ventrolateral incision. Each frog received a blank or hormone implant, inserted intra-abdominally, before the incision was sealed with a combination of nylon non-absorbable sutures (CP Medical; Portland, Oreg., USA) and Vetbond (World Precision Instruments, Sarasota, Fla., USA). After several days of recovery in in- dividual cages, the frogs were group housed, by hormone treatment, until the acoustic procedure was started 7 days after surgery. Pilot studies determined that endogenous androgens and estrogen are depleted within 7 days after gonadectomy [Almli, unpubl. obs.]. Following the acoustic stimulation procedure, we euthanized the animals and collected blood samples for hormone analysis. Gonadectomy and implantation did not seem to differentially affect the health of the animals as measured by the mass of the animal before and after the acoustic stimulation procedure (female - Blank before: $8.1 \pm 0.3$ g, after: $7.8 \pm 0.4$ g; Estrogen before: $8.0 \pm 0.3 \mathrm{~g}$, after: $7.7 \pm 0.4 \mathrm{~g}$; male - Blank before: $7.6 \pm$ $0.3 \mathrm{~g}$, after: $7.5 \pm 0.2 \mathrm{~g}$; Testosterone before: $6.7 \pm 0.2 \mathrm{~g}$, after: 7.0 $\pm 0.2 \mathrm{~g})$.

\section{Acoustic Stimulation Procedure}

The acoustic stimulation procedure was modified from methods detailed previously [Almli and Wilczynski, 2009]. Each treefrog was housed individually in an acoustically isolated test chamber $(14 \times 14 \times 20 \mathrm{~cm})$ containing water, plastic plants, rocks, and a light on a timer. The acoustic chamber contained a speaker (Radioshack 277-1008C) connected to a tape deck for presenting acoustic stimuli and a microphone connected to a custom-designed circuit board. The output of the board connected to a computer with custom-designed software that counted each male subject's calls.

Gonadectomized and implanted $H$. cinerea were exposed to either a recording of a natural chorus ('Chorus') or random pure tones ('Tone') between 21:00 and 2:00 (typical of a breeding chorus) on 9 consecutive nights. The Tone stimulus was generated using SoundEdit 16 (Macromedia, Inc.) by replacing each frog call in the Chorus stimulus with a single pure tone that matched the call in duration and approximate amplitude. Due to a limitation in the number of acoustic chambers available, male and female treefrogs were divided into two groups, or 'cohorts' (cohort 1: 12 males and 13 females; cohort 2: 14 males and 15 females), with animals in each cohort gonadectomized and implanted 7 days prior to the acoustic stimulation procedure. Within each sex, the subjects were divided equally by hormone and acoustic treatment type (Chorus or Tone). After sacrifice on day 10, trunk plasma samples were taken and stored at $-20^{\circ} \mathrm{C}$ for steroid hormone analysis.

\section{BrdU Immunofluorescence and Cell Proliferation Analysis}

During the acoustic stimulation procedure, frogs were injected with BrdU (100 mg/kg in saline; Sigma) at 20:30 on days 1, 5, and 9, and sacrificed between 10:00-12:00 on day 10. Brains were removed, immersion-fixed in $4 \%$ paraformaldehyde, and cryoprotected in $20 \%$ sucrose. Brain tissue was sectioned on a cryostat into 4 series; sections ( $20 \mu \mathrm{m}$ thick) were collected on gelatinized subbed slides and stored at $-20^{\circ} \mathrm{C}$ until immunofluorescence staining was carried out. One series of brain sections (every fourth section in total) was processed for BrdU using the 5-bromo-2'deoxyuridine Labeling and Detection Kit I (Roche Applied Science, Indianapolis, Ind., USA). For detection of BrdU-labeled nuclei, the DNA was denatured with $2 \mathrm{~N} \mathrm{HCl}$ at $37^{\circ} \mathrm{C}$ and neutralized with $0.1 \mathrm{M}$ boric acid buffer ( $\mathrm{pH}$ 8.5). Nonspecific antigen binding sites were blocked by preincubation with blocking solution containing $10 \%$ normal sheep serum. Slides were incubated with anti-BrdU antibody $(1: 100)$ at $37^{\circ} \mathrm{C}$ followed by fluorescein-labeled anti-mouse secondary antibody $(1: 100)$ to visualize BrdU-positive 
cells. Slides were coverslipped using Fluoromount - G (Electron Microscopy Science, Hatfield, Pa., USA). Omission of the primary antibody eliminated all specific staining.

Slides were coded so that cell counts were obtained blind to experimental conditions. Fluorescein-positive cells (i.e. BrdU+ cells) were visualized and counted under a FITC filter cube using a $40 \times$ objective (Olympus BX60 microscope). Every section in the stained series was counted to determine the numbers of labeled cells in the POA and IF using published boundaries [in Northcutt and Kicliter, 1980; Neary and Northcutt, 1983]. The quantification procedure, using the fractionator method [West et al., 1991], consisted of multiplying the cell counts by four to obtain an estimate of the total number of labeled cells per region of interest, because every fourth section was sampled. Previous studies have determined that correcting the total number of cells by the volume of the sections sampled does not influence the results [Almli and Wilczynski, 2009]. Subjects that were missing consecutive sections within the POA or IF or had sections with aberrant staining were excluded from analyses. The resultant number of animals per group is listed under each analysis in the Results section.

\section{Gonadal Steroid Hormone Analysis}

To verify the effectiveness of the hormone manipulation, we used an enzyme immunoassay kit (EIA; Cayman Chemical, Ann Arbor, Mich., USA) to measure levels of androgens and estrogen in males and females, respectively. General methods for the EIA procedure have been previously described [Almli and Wilczynski, 2009]. The volume of plasma used in each estradiol assay was 8 and $50 \mu l$ (estrogen implants and blanks, respectively) and 5 and $8 \mu \mathrm{l}$ for androgen (testosterone implants and blanks, respectively). Plasma samples were spiked with $20 \mu$ l of tritiated estradiol or testosterone and extracted using $3 \mathrm{ml}$ of diethyl ether. The extraction procedure resulted in a mean recovery \pm the standard error of the mean (SEM) of $24.8 \pm 0.5 \%$ for estrogen and $80.3 \pm 1.4 \%$ for androgen. Recovery values were used to correct the concentration of hormone estimated in each sample. We assayed each sample in this study in triplicate and used between 1 and 3 dilutions per sample. In males, testosterone implants yielded a mean androgen level of $110.3 \pm 5.9 \mathrm{ng} / \mathrm{ml}$ and blanks yielded $2.1 \pm 0.2 \mathrm{ng} /$ $\mathrm{ml}$. In females, estrogen implants yielded a mean estradiol level of $17.1 \pm 1.4 \mathrm{ng} / \mathrm{ml}$; the estradiol levels of the female frogs that received blank implants were undetectable. For statistical purposes, the estradiol levels were assigned a value of $0.008 \mathrm{ng} / \mathrm{ml}$ (or $8 \mathrm{pg}$ / $\mathrm{ml}$, the detection limit of the kit) for blank implants. Inter-assay variation was 13.6 and $6.6 \%$ in the estradiol and androgen assays, respectively. Intra-assay variation was 6.4 and $7.1 \%$ in the estradiol and androgen assays, respectively. Cross-reactivity in the estrogen kit was $0.1 \%$ for testosterone and $5 \alpha$-dihydrotestosterone, $0.07 \%$ for $17 \alpha$-estradiol, and $0.03 \%$ for progesterone. The testosterone kit had $27.4 \%$ cross-reactivity with $5 \alpha$-dihydrotestosterone and $18.9 \%$ for $5 \beta$-dihydrotestosterone. The detection limits were $8 \mathrm{pg} / \mathrm{ml}$ and $6 \mathrm{pg} / \mathrm{ml}$ for the estradiol and testosterone EIA kits, respectively. The EIA kits were previously validated by extracting hormone from a pooled plasma sample, and comparing that serially-diluted sample (with 3 dilutions) to the standard curve for that hormone [Almli and Wilczynski, 2009].

Statistical Analysis

All statistical analyses were conducted with SPSS 18.0 (SPSS Inc., Chicago, Ill., USA, 2009), and p values were considered sig- nificant at $\mathrm{p}<0.05$. For both male and female treefrogs, the numbers of BrdU+ cells in the POA and IF were analyzed with a threeway MANOVA with cohort (1 or 2), implant (in males: Testosterone or Blank; in females: Estrogen or Blank), and acoustic stimulus type (Chorus or Tone) as independent variables. Posthoc analyses using the Tukey procedure were planned a priori to determine whether particular subgroups might be driving any significant main effects. Correlation analyses were conducted with evoked calling behavior in males and the number of BrdU+ cells in the POA and IF; and if significant, an ANCOVA was conducted on the number of proliferating cells using evoked calling as a covariate.

\section{Results}

We use the term cell proliferation to describe the component of neurogenesis observed in this study, but we note that we may be observing several processes of adult neurogenesis with our procedure (e.g. cell proliferation and/or survival) given the timeline of BrdU injections (e.g. days 1, 5, and 9). Proliferating cells, labeled with BrdU, were found in or near the ventricular zone of the POA (fig. 1) and IF (containing the ventral and dorsal hypothalamus, the posterior tuberculum, and the nucleus of the periventricular organ; fig. 2). Labeled cells were also found in the parenchymal areas of the POA and IF, though they were lesser in number.

\section{Proliferating Cell Numbers Increase in Male Treefrogs Hearing Their Conspecific Chorus}

A MANOVA was conducted with the number of BrdU+ cells in the POA and IF as dependent variables and cohort (1: $\mathrm{n}=12$ or $2: \mathrm{n}=14)$, acoustic stimulus type (Chorus: $\mathrm{n}=11$ or Tone: $\mathrm{n}=15$ ) and hormone implant (Testosterone: $\mathrm{n}=13$ or Blank: $\mathrm{n}=13$ ) as independent variables. Because the cohort variable did not significantly affect the dependent variables, and there were no significant interactions between cohort and main effects, it was collapsed and the analysis was recalculated. In males, there was a main effect of acoustic stimulus type $(\lambda=$ $\left.0.644, F_{2,21}=5.793, \mathrm{p}=0.010\right)$ on the number of BrdU+ cells, but no main effect of hormone implant $(\lambda=0.981$, $F_{2,21}=0.198, \mathrm{p}=0.822$ ). There was no significant interaction between acoustic stimulus type and hormone implant $\left(\lambda=0.974, F_{2,21}=0.281, \mathrm{p}>0.758\right)$. Between-subject analyses on the number of BrdU+ cells in the POA $\left(F_{1,22}=8.251, \mathrm{p}=0.009\right)$ and $\operatorname{IF}\left(F_{1,22}=8.065, \mathrm{p}=0.010\right)$ indicate that each area was affected by the acoustic stimulus treatment: the Chorus-stimulated males exhibited increased numbers of proliferating cells compared to Tone controls (fig. 3). Although the pattern between the 

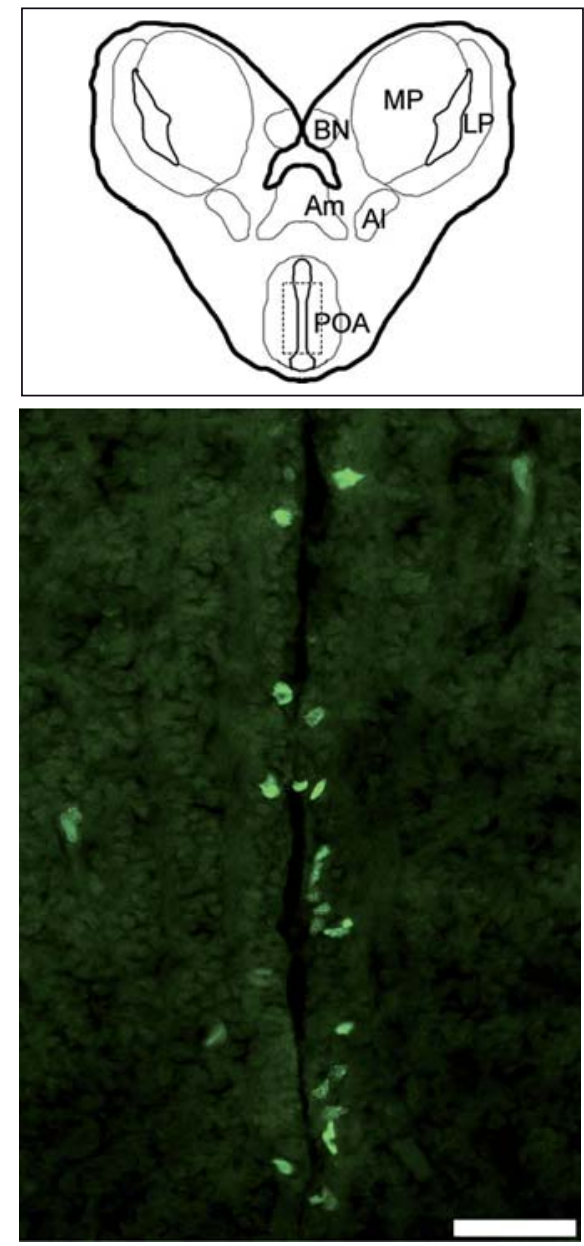

Fig. 1. Schematic and photomicrograph of a horizontal section through the telencephalon of a representative $H$. cinerea brain at the level of the POA. The dotted rectangle in the upper image represents the area including the preoptic recess photographed in the lower image. BrdU-labeled cells (i.e. green cells) are located mainly near the ventricle edge in the center of the image. Scale bar $=$ $50 \mu \mathrm{m} . \mathrm{Al}=$ Lateral amygdala $; \mathrm{Am}=$ medial amygdala $; \mathrm{BN}=$ bed nucleus of the pallial commissure; $\mathrm{LP}=$ lateral pallidum; $\mathrm{MP}=$ medial pallidum.

effects of Chorus and Tone-stimulation on cell proliferation is the same in each hormone implant group, post-hoc tests reached significance in the testosterone-implanted males in the POA ( $p=0.016$; fig. $3 \mathrm{a})$ and IF ( $\mathrm{p}=0.023$; fig. 3b).

\section{Evoked Calling Behavior Is Not Driving Socially}

Modulated Cell Proliferation in Male Treefrogs

In order to determine the effects of calling behavior on cell proliferation, correlations between evoked calling and cell proliferation in the POA and IF were conducted.
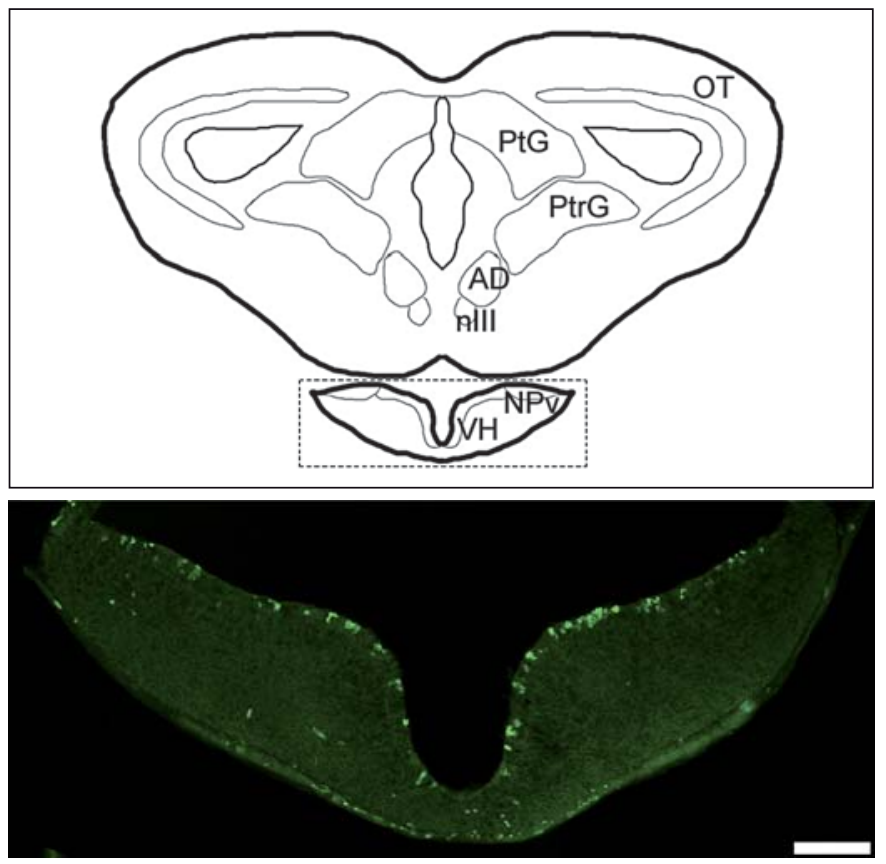

Fig. 2. Schematic and photomicrograph of a horizontal section through the telencephalon of a representative $H$. cinerea brain at the level of the IF. The dotted rectangle in the upper image represents the area including the hypothalamic recess photographed in the lower image. BrdU-labeled cells (i.e. green cells) are located mainly near the ventricle edge in the center of the image. Scale bar $=100 \mu \mathrm{m} . \mathrm{AD}=$ Anterodorsal tegmentum; $\mathrm{nIII}=$ oculomotor nucleus; $\mathrm{NPv}=$ nucleus of the periventricular organ; $\mathrm{OT}=$ optic tectum; $\mathrm{PtG}=$ pretectal gray; $\mathrm{PtrG}=$ pretoral gray.

Using only males that called back to acoustic stimulation, a significant positive correlation was observed between calling behavior and cell proliferation in the POA $(\mathrm{r}=$ $0.697, \mathrm{p}=0.037$; fig. 4), but not in the IF ( $\mathrm{p}>0.1$ ). To statistically control for calling behavior, an ANCOVA was conducted on the number of BrdU+ cells in the POA with the number of evoked calls as a covariate. This analysis included only males that engaged in evoked calling behavior, which was a portion of the testosterone-implanted males as sufficient levels of testosterone are necessary to engage in calling behavior. A significant effect of acoustic stimulation after statistically controlling for the number of evoked calls $\left(F_{1,7}=7.245, \mathrm{p}=0.031\right.$; covariate: $F_{1,7}=$ $0.035, \mathrm{p}=0.857)$ confirmed that calling back to acoustic stimuli was not driving the social modulation of cell proliferation in the POA. Overall, this analysis suggests that in male treefrogs, hearing their conspecific chorus was sufficient to exhibit increases in cell proliferation in the POA without regard to calling behavior. 
Fig. 3. Influence of testosterone implants and acoustic stimulation on the number of BrdU+ cells in the POA and IF of male $H$. cinerea. Males exhibited increased cell proliferation in the POA (a) and IF (b) in response to hearing their conspecific Chorus compared to Tone controls. Shown are the mean total number of cells per region of interest $[ \pm$ the standard error of the mean (SEM)]. Significant post-hoc tests are represented by asterisks.

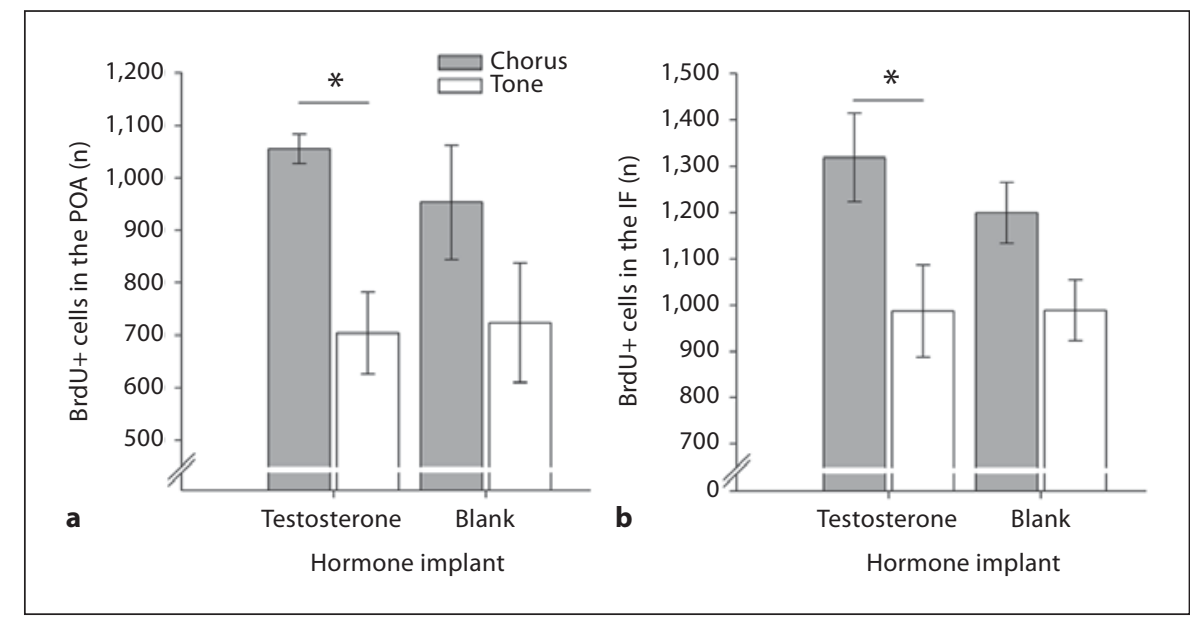

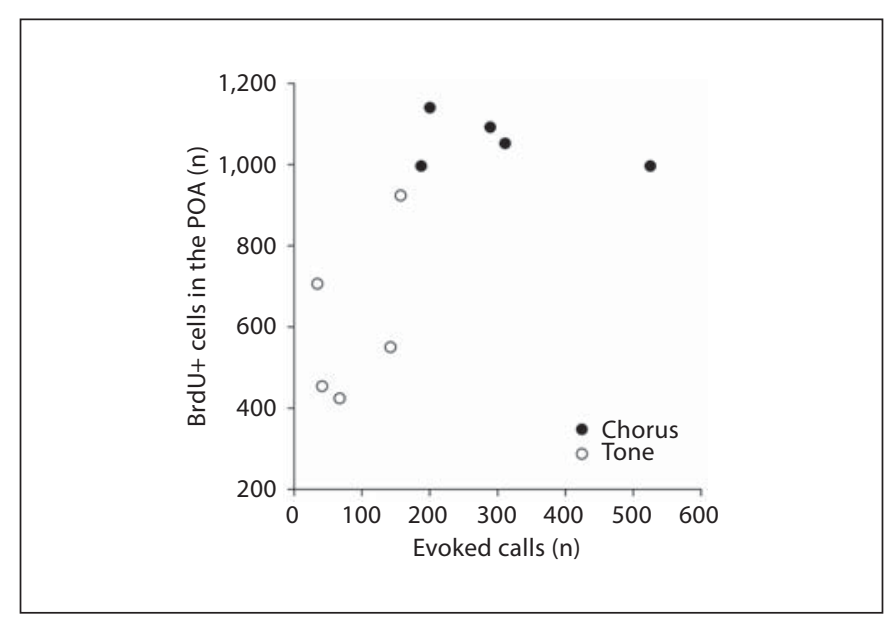

Fig. 4. Relationship between the number of evoked calls and the number of BrdU+ cells in the POA of male H. cinerea. There was a significant positive correlation between calling behavior and cell proliferation in the male POA $(r=0.697, \mathrm{p}=0.035)$.

\section{Estradiol Decreased Proliferating Cell Numbers in Female Treefrogs and Is Not Necessary for Socially Modulated Cell Proliferation}

A MANOVA was conducted with the number of BrdU+ cells in the POA and IF as dependent variables and cohort $(1: \mathrm{n}=13$ or $2: \mathrm{n}=15)$, acoustic stimulus type (Chorus: $\mathrm{n}=14$ or Tone: $\mathrm{n}=14$ ) and hormone implant (Estrogen: $\mathrm{n}=14$ or Blank: $\mathrm{n}=14$ ) as independent variables. Again, the cohort variable did not significantly affect the dependent variables, and there were no significant interactions between cohort and main effects; thus, the variable was collapsed and the analysis recal- culated. Overall, in females, there was no main effect of acoustic stimulus type $\left(\lambda=0.860, F_{2,23}=1.879, \mathrm{p}=\right.$ 0.175 ) on the number of BrdU+ cells, but there was a significant main effect of hormone implant $\left(\lambda=0.323, F_{2}\right.$, $\left.{ }_{23}=24.149, \mathrm{p}<0.001\right)$. There was no significant interaction between acoustic stimulus type and hormone implant $\left(\lambda=0.929, F_{2,23}=0.874, \mathrm{p}>0.431\right)$. Estrogen implants significantly decreased BrdU+ cell numbers in the POA $\left(F_{1,24}=39.820, \mathrm{p}<0.001\right.$; fig. $\left.5 \mathrm{a}\right)$ and $\operatorname{IF}\left(F_{1,24}=\right.$ $21.800, \mathrm{p}<0.001$; fig. $5 \mathrm{~b})$. Significant post-hoc tests revealed that the females with undetectable levels of estrogen (i.e. blank implants) exhibited socially induced increases in cell proliferation in the IF ( $p=0.016$; fig. $5 b$ ) but not the POA $(\mathrm{p}>0.1)$.

\section{Discussion}

As a follow-up to our previous study [Almli and Wilczynski, 2009], we examined the potential influence of gonadal hormones on BrdU-immunoreactivity in the brains of gonadectomized and implanted male and female $H$. cinerea to determine whether these hormones were necessary for the social modulation of cell proliferation. (As noted previously, we are defining BrdU-immunoreactivity as proliferative activity in light of the unresolved timeline of cell proliferation, migration, and maturation in anurans in addition to our BrdU injection scheme, though it is possible that the differences seen may be in rates of survival and not proliferation.) Our results demonstrated that socially induced increases in cell proliferation were independent of gonadal steroid levels in male and female green treefrogs. Using acoustic 
Fig. 5. Influence of estrogen implants and acoustic stimulation on the number of BrdU+ cells in the POA and IF of female $H$. cinerea. Estrogen implants significantly decreased cell proliferation in the POA (a) and IF (b). Females with undetectable levels of estrogen $(<8 \mathrm{pg} / \mathrm{ml})$ exhibited socially modulated cell proliferation in the IF as revealed by a significant post-hoc test (represented by an asterisk). Shown are means \pm SEM.

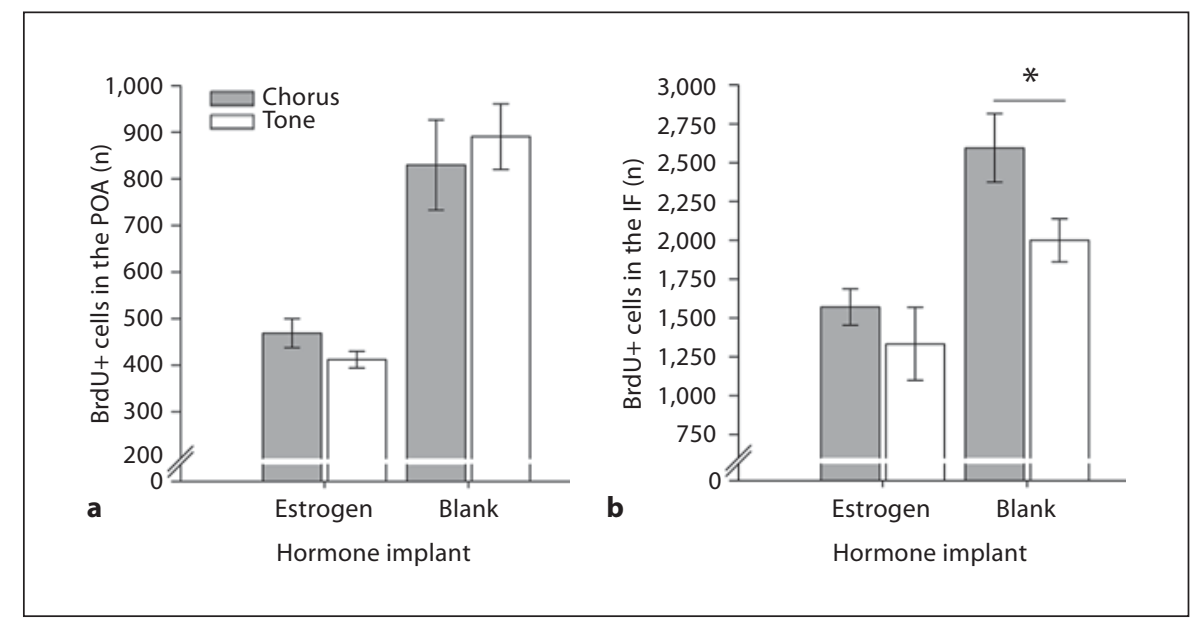

social cues, we demonstrated that cell proliferation was socially modulated in the POA and IF, brain regions involved in the expression of socio-sexual behaviors as well as associated endocrine responses. We found that androgen levels in males did not modulate the number of proliferating cells as labeled by BrdU incorporation, and the pattern of BrdU+ cell increase was the same in testosterone- and blank-implanted animals (although reaching significance in post-hoc tests in the testosterone-implanted group only). Furthermore, elevated estrogen levels in females suppressed cell proliferation, and post-hoc tests revealed a socially induced increase in BrdU+ cells in the IF in ovariectomized, blank-implanted animals after Chorus exposure.

Both testosterone and estrogen implants yielded hormone levels within the physiological range; however, the levels were significantly higher than those of unmanipulated frogs (testosterone implants: $110.3 \pm 5.9$ vs. $12-14$ $\mathrm{ng} / \mathrm{ml}$ for unmanipulated males; estrogen implants: 17.1 $\pm 1.4 \mathrm{vs} .4-5 \mathrm{ng} / \mathrm{ml}$ for unmanipulated females [Almli, unpubl. obs.]). In the two regions studied here, it is clear that gonadal hormones affect cell proliferation in the sexes differently. Testosterone alone did not modulate cell proliferation in the POA and IF as evidenced by comparable numbers of BrdU+ cells in the males that heard Tones with and without a testosterone implant. However, given that significant socially induced increases in cell proliferation were reached only in post-hoc tests in the testosterone-implanted group, it is possible that testosterone does not directly affect socially induced increases in cell proliferation, but may indeed facilitate the process. In female treefrogs, high estrogen levels decreased cell proliferation in the POA and IF compared to control levels in females with undetectable estrogen levels (i.e. blankimplanted females).

In other vertebrates, testosterone appears to increase the survival, but not the proliferation, of new cells [reviewed in Galea, 2008]. In songbirds, testosterone enhances the survival of HVC neurons [Goldman and Nottebohm, 1983; Rasika et al., 1994; for an exception, see Brown et al., 1993]. In mammals, Ormerod and Galea [2003] found increased cell survival in the hippocampus when testosterone levels were naturally high during the breeding season compared to outside the breeding season. However, cell proliferation is not similarly enhanced with high testosterone levels [Galea and McEwen, 1999; Ormerod and Galea, 2003]. Further, exogenous testosterone has been shown to increase cell survival in the rat hippocampus [Spritzer and Galea, 2007] and amygdala (voles [Fowler et al., 2003] and hamsters [Antzoulatos et al., 2008]); however, there was no effect in the medial POA on cell proliferation or survival [Antzoulatos et al., 2008]. Thus, in many brain regions, it seems that testosterone alone does not affect cell proliferation in male vertebrates, an observation supported by our results. This does not rule out the potential for a testosterone-dependent increase in cell survival in amphibians as in other organisms, but this mechanism was not investigated in our study. Given the timeline of cell proliferation/migration in this species [Almli and Wilczynski, 2007] and the injection paradigm, our study would likely not pick up a significant effect on cell survival within the 10 days of social stimulation.

Estradiol, on the other hand, has been traditionally considered neuroprotective [e.g. Brann et al., 2007] with acute estradiol administration enhancing cell prolifera- 
tion [e.g. Tanapat et al., 1999; Banasr et al., 2001]. However, high (and chronic) estrogen levels have been shown to inhibit or decrease the process of adult neurogenesis in rodents [Galea and McEwen, 1999; Ormerod and Galea, 2001; Ormerod et al., 2003; Barker and Galea, 2008]. Likewise, others have also reported a dose-response relationship for estrogen, such that low doses facilitate but high doses inhibit cellular, molecular, and/or behavioral responses [e.g. Cheng, 1977; Scharfman and MacLusky, 2006]. Specifically regarding neurogenesis, a mechanism for the inhibition of cell proliferation and/or survival with high estrogen levels has been suggested by Barker and Galea [2008]: chronic estrogen 'may alter the responsiveness of cells to estradiol itself (via regulating estrogen receptors), potentially reversing the survival-enhancing effects of acute estradiol exposure.' This negative feedback regulation could be due to the down-regulation of estrogen receptors (ER) [Weiland et al., 1997] as evidenced by decreased ER $\alpha$ gene expression in ovariectomized rodents receiving chronic estradiol treatment [Jin et al., 2005; Iivonen et al., 2006]. In our study in frogs, plasma estradiol levels were approximately four times higher than those of naturally-cycling females [Almli and Wilczynski, 2009]. These levels may still be much higher than reported plasma estradiol in amplexing ovulatory females, which yield the highest levels compared to other reproductive stages in anurans [Gobbetti and Zerani, 1999; Lynch and Wilczynski, 2005]. Such homeostatic adaptation resulting from high estrogen levels may explain the loss of a significant overall main effect of socially modulated increases in cell proliferation in female frogs in the current study in contrast to that previously reported in hormonally unmanipulated animals [Almli and Wilczynski, 2009]. Indeed, it is noteworthy that in this study blank-implanted females, which had low to undetectable estrogen levels and were therefore released from the suppressive effects of estrogen, exhibited increased cell proliferation in the IF of the Chorus-stimulated group.

We also previously reported that in adult males and females in naturally cycling reproductive condition, hearing acoustic social signals increased cell proliferation in the POA and IF but did not upregulate cell proliferation in general [Almli and Wilczynski, 2009]. In our current study, Chorus-stimulation increased BrdU+ cell numbers in the POA and IF of male $H$. cinerea, but female $H$. cinerea exhibited Chorus-stimulated increases in BrdU+ cell numbers only in the IF. This region- and sex-specific difference in the social modulation of cell proliferation may be consistent with the sexually-dimor-

Socially Modulated Cell Proliferation in Hyla cinerea phic functions of the POA and IF. For example, male sexual behavior is linked to the POA: lesions of the POA abolish male sexual behavior in anurans [Schmidt, 1968; Urano, 1988] and stimulating the POA elicits evoked calling behavior [Schmidt, 1968; Knorr, 1976; Wada and Gorbman, 1977b]. On the other hand, female sexual behavior is linked to the $\mathrm{VH}$, a component of the IF, in other vertebrate groups (in mammals [Pfaff and Schwartz-Giblin, 1988]; and reptiles [Wade and Crews, 1991; Kendrick et al., 1995]). However, the neural correlates of female anuran reproductive behavior (i.e. phonotaxis) are unresolved at this time. In addition to being the reproductive centers of the basal forebrain, the POA and $\mathrm{VH}$ receive auditory information from thalamic and midbrain nuclei [Wilczynski et al., 1993; Emerson and Boyd, 1999; Wilczynski and Endepols, 2007] and contain neurons that respond to a conspecific chorus [Wilczynski and Allison, 1989; Allison, 1992]. In contrast to our previous study, we did find increased cell proliferation in the IF in addition to the POA in Chorus-stimulated male anurans. Although the pattern of cell proliferation is similar in both studies, the observation that both brain regions reached significance here as opposed to our previous study may be due to variance or other unknown factors.

We observed that gonadal hormones were not necessary for the social modulation of cell proliferation in $H$. cinerea. In the limited studies exploring this in other organisms, it seems that the relationship between gonadal hormones and socially modulated neurogenesis depends on the sex, species, and experimental design. For example, social behavior, as measured by mating activity, did not enhance cell proliferation in the medial POA of male hamsters nor was it mediated by testosterone [Antzoulatos et al., 2008]. In female prairie voles, male exposure and mating activity did enhance cell proliferation/survival in the VH [Fowler et al., 2002], but this effect was not mediated by estrogen [Fowler et al., 2005]. What may be driving these socially induced changes in cell proliferation or survival is beyond the scope of this study. However, candidate mechanisms include the regional induction of neurotrophic factors, such as brain-derived neurotrophic factor, as shown by research in other vertebrates [Li et al., 2000; Pencea et al., 2001; Alvarez-Borda et al., 2004], or other steroid hormones such as corticosteroids, which traditionally negatively affect neurogenesis in mammals [e.g. Gould et al., 1992] but positively affect cell proliferation in weakly electric fishes [Dunlap et al., 2006, 2008]. Their effects on proliferative activity in anuran amphibians are unknown at this time. 
Behavioral responses to social stimuli have been known to affect adult neurogenesis [e.g. Sartor and Ball, 2005]. As reported in other studies, calling depends on the presence of androgens [Wada et al., 1976; Wada and Gorbman, 1977a; Wetzel and Kelley, 1983; Solis and Penna, 1997; Burmeister and Wilczynski, 2001], as castrated treefrogs in our study did not call. Evoked calling behavior was positively correlated with cell proliferation in the POA and not in the IF, which is interesting considering the involvement of the POA in calling behavior. However, the behavioral response of calling was not driving the socially induced increases in BrdU-labeling in the POA, as demonstrated statistically by controlling for the amount of evoked calling behavior. Thus, unlike that observed in the song control nuclei of songbirds [Wang et al., 1999; Sartor and Ball, 2005] and potentially in the electrocommunication circuitry of electric fish [Dunlap et al., 2006, $2008,2011]$, the behavioral output of male treefrogs in this study did not influence cell proliferation in the brain regions studied here.

In conclusion, our results indicate that acoustic social stimuli modulate cell proliferation independent of gonadal hormones in the green treefrog. In addition, go- nadal hormones differentially influence cell proliferation: testosterone in the male treefrog did not affect cell proliferation, whereas elevated estrogen levels in the female suppressed cell proliferation. There were sex differences in the location of socially modulated cell proliferation: in the male, socially induced cell proliferation occurred in the POA and IF, whereas in the female, socially induced increases occurred in the IF. Additionally, in males, evoked calling behavior was positively correlated with BrdU-labeling in the POA (and not the IF); however, this behavior did not mediate socially induced cell proliferation. Even though gonadal steroids may rise in concert with increased cell proliferation, it appears that they are not interdependent with the effects on cell proliferation from social modulation.

\section{Acknowledgements}

We thank Glennis Julian for assistance with the gonadal hormone analysis, in addition to Deborah Lutterschmidt and several anonymous reviewers for comments on the manuscript. Funding was provided by Sigma Xi to L.M.A. and the National Institutes of Health (R01 MH057066 to W.W. and F31 MH077457 to L.M.A).

\section{References}

Allison JD (1992): Acoustic modulation of neural activity in the preoptic area and ventral hypothalamus of the green treefrog (Hyla cinerea). J Comp Physiol A 171:387-395.

Almli LM, Wilczynski W (2007): Regional distribution and migration of proliferating cell populations in the adult brain of Hyla cinerea (Anura, Amphibia). Brain Res 1159:112-118.

-Almli LM, Wilczynski W (2009): Sex-specific modulation of cell proliferation by socially relevant stimuli in the adult green treefrog brain (Hyla cinerea). Brain Behav Evol 74: 143-154.

-Alvarez-Borda B, Haripal B, Nottebohm F (2004): Timing of brain-derived neurotrophic factor exposure affects life expectancy of new neurons. Proc Natl Acad Sci 101: 3957-3961.

Antzoulatos E, Magorien JE, Wood RI (2008): Cell proliferation and survival in the mating circuit of adult male hamsters: effects of testosterone and sexual behavior. Horm Behav 54:735-740.

-Banasr M, Hery M, Brezun JM, Daszuta A (2001): Serotonin mediates oestrogen stimulation of cell proliferation in the adult dentate gyrus. Eur J Neurosci 14:1417-1424.
Barker JM, Galea LA (2008): Repeated estradiol administration alters different aspects of neurogenesis and cell death in the hippocampus of female, but not male, rats. Neuroscience 152:888-902.

Barnea A, Mishal A, Nottebohm F (2006): Social and spatial changes induce multiple survival regimes for new neurons in two regions of the adult brain: an anatomical representation of time? Behav Brain Res 167:63-74.

-Baudoin C, Busquet N, Dobson FS, Gheusi G, Feron C, Durand JL, Heth G, Patris B, Todrank J (2005): Male-female associations and female olfactory neurogenesis with pair bonding in Mus spicilegus. Biol J Linn Soc 84: 323-334.

Bosch J, Boyero L (2004): Reproductive stage and phonotatic preferences of female midwife toads (Alytes cisternasii). Behav Ecol and Sociobiol 55:251-256.

Brann DW, Dhandapani K, Wakade C, Mahesh VB, Khan MM (2007): Neurotrophic and neuroprotective actions of estrogen: basic mechanisms and clinical implications. Steroids $72: 381-405$.

Brown SD, Johnson F, Bottjer SW (1993): Neurogenesis in adult canary telencephalon is independent of gonadal hormone levels. J Neurosci 13:2024-2032.
Burmeister S, Wilczynski W (2000): Social signals influence hormones independently of calling behavior in the treefrog (Hyla cinerea). Horm Behav 38:201-209.

Burmeister SS, Wilczynski W (2001): Social context influences androgenic effects on calling in the green treefrog (Hyla cinerea). Horm Behav 40:550-558.

Burmeister SS, Wilczynski W (2005): Social signals regulate gonadotropin-releasing hormone neurons in the green treefrog. Brain Behav Evol 65:26-32.

Chakraborty M, Burmeister SS (2009): Estradiol induces sexual behavior in female tungara frogs. Horm Behav 55:106-112.

Cheng MF (1977): Role of gonadotropin releasing hormones in the reproductive behaviour of female ring doves (Streptopelia risoria). J Endocrinol 74:37-45.

Chu J, Wilczynski W (2001): Social influences on androgen levels in the Southern leopard frog, Rana sphenocephala. Gen Comp Endocrinol 121:66-73.

Dunlap KD, Castellano JF, Prendaj E (2006): Social interaction and cortisol treatment increase cell addition and radial glia fiber density in the diencephalic periventricular zone of adult electric fish, Apteronotus leptorhynchus. Horm Behav 50:10-17. 
-Dunlap KD, McCarthy EA, Jashari D (2008): Electrocommunication signals alone are sufficient to increase neurogenesis in the brain of adult electric fish, Apteronotus leptorhynchus. Dev Neurobiol 68:1420-1428.

Dunlap KD, Silva AC, Chung M (2011): Environmental complexity, seasonality and brain cell proliferation in a weakly electric fish, Brachyhypopomus gauderio. J Exp Biol 214: 794-805.

Emerson SB, Boyd SK (1999): Mating vocalizations of female frogs: control and evolutionary mechanisms. Brain Behav Evol 53:187197.

Fowler CD, Freeman ME, Wang Z (2003): Newly proliferated cells in the adult male amygdala are affected by gonadal steroid hormones. J Neurobiol 57:257-269.

- Fowler CD, Johnson F, Wang Z (2005): Estrogen regulation of cell proliferation and distribution of estrogen receptor-alpha in the brains of adult female prairie and meadow voles. J Comp Neurol 489:166-179.

-Fowler CD, Liu Y, Ouimet C, Wang Z (2002): The effects of social environment on adult neurogenesis in the female prairie vole. J Neurobiol 51:115-128.

-Fowler CD, Liu Y, Wang Z (2008): Estrogen and adult neurogenesis in the amygdala and hypothalamus. Brain Res Rev 57:342-351.

-Galea LA (2008): Gonadal hormone modulation of neurogenesis in the dentate gyrus of adult male and female rodents. Brain Res Rev 57: 332-341.

Galea LA, McEwen BS (1999): Sex and seasonal differences in the rate of cell proliferation in the dentate gyrus of adult wild meadow voles. Neuroscience 89:955-964.

Gerhardt HC (1988): Acoustic properties used in call recognition by frogs and toads; in Fritzsh B, Ryan MJ, Wilczynski W, Hetherington TE, Walkowiak W (eds): The Evolution of the Auditory System. New York, Wiley \& Sons, pp 455-483.

-Gheusi G, Ortega-Perez I, Murray K, Lledo PM (2009): A niche for adult neurogenesis in social behavior. Behav Brain Res 200:315-322.

Gobbetti A, Zerani M (1999): Hormonal and cellular brain mechanisms regulating the amplexus of male and female water frog (Rana esculenta). J Neuroendocrinol 11:589-596.

-Gobbetti A, Zerani M, Bolelli GF, Botte V (1991): Seasonal changes in plasma prostaglandin F2 alpha and sex hormones in the male water frog, Rana esculenta. Gen Comp Endocrinol 82:331-336.

Goldman SA, Nottebohm F (1983): Neuronal production, migration, and differentiation in a vocal control nucleus of the adult female canary brain. Proc Natl Acad Sci 80:23902394.

Gordon NM, Gerhardt HC (2009): Hormonal modulation of phonotaxis and advertisement-call preferences in the gray treefrog (Hyla versicolor). Horm Behav 55:121-127.
Gould E, Cameron HA, Daniels DC, Woolley CS, McEwen BS (1992): Adrenal hormones suppress cell division in the adult rat dentate gyrus. J Neurosci 12:3642-3650.

- Iela L, Rastogi RK, Delrio G, Bagnara JT (1986): Reproduction in the Mexican leaf frog, Pachymedusa dacnicolor. III. The female. Gen Comp Endocrinol 63:381-392.

Iivonen S, Heikkinen T, Puolivali J, Helisalmi S, Hiltunen M, Soininen H, Tanila H (2006): Effects of estradiol on spatial learning, hippocampal cytochrome P450 19, and estrogen alpha and beta mRNA levels in ovariectomized female mice. Neuroscience 137:1143-1152.

Itoh M, Inoue M, Ishii S (1990): Annual cycle of pituitary and plasma gonadotropins and plasma sex steroids in a wild population of the toad, Bufo japonicus. Gen Comp Endocrinol 78:242-253.

Itoh M, Ishii S (1990): Changes in plasma levels of gonadotropins and sex steroids in the toad, Bufo japonicus, in association with behavior during the breeding season. Gen Comp Endocrinol 80:451-464.

Jin M, Jin F, Zhang L, Chen Z, Huang H (2005): Two estrogen replacement therapies differentially regulate expression of estrogen receptors alpha and beta in the hippocampus and cortex of ovariectomized rat. Brain Res Mol Brain Res 142:107-114.

Kelley DB (1982): Female sex behaviors in the South African clawed frog, Xenopus laevis: gonadotropin-releasing, gonadotropic, and steroid hormones. Horm Behav 16:158-174.

Kelley DB, Pfaff DW (1976): Hormone effects on male sex behavior in adult South African clawed frogs, Xenopus laevis. Horm Behav 7: 159-182.

Kendrick AM, Rand MS, Crews D (1995): Electrolytic lesions to the ventromedial hypothalamus abolish receptivity in female whiptail lizards, Cnemidophorus uniparens. Brain Res 680:226-228.

Knorr A (1976): Central control of mating call production and spawning in the tree frog Hyla arborea savignyi (Audouin): results of electrical stimulation of the brain. Behav Process 1:295-317.

Lea J, Halliday T, Dyson M (2000): Reproductive stage and history affect the phonotactic preferences of female midwife toads, Alytes muletensis. Anim Behav 60:423-427.

Li XC, Jarvis ED, Alvarez-Borda B, Lim DA, Nottebohm F (2000): A relationship between behavior, neurotrophin expression, and new neuron survival. Proc Natl Acad Sci 97: 8584-8589.

Licht P, McCreery BR, Barnes R, Pang R (1983): Seasonal and stress related changes in plasma gonadotropins, sex steroids, and corticosterone in the bullfrog, Rana catesbeiana. Gen Comp Endocrinol 50:124-145.

Lipkind D, Nottebohm F, Rado R, Barnea A (2002): Social change affects the survival of new neurons in the forebrain of adult songbirds. Behav Brain Res 133:31-43.
Lynch KS, Crews D, Ryan MJ, Wilczynski W (2006): Hormonal state influences aspects of female mate choice in the Tungara Frog (Physalaemus pustulosus). Horm Behav 49:450457.

Lynch KS, Wilczynski W (2005): Gonadal steroids vary with reproductive stage in a tropically breeding female anuran. Gen Comp Endocrinol 143:51-56.

Lynch KS, Wilczynski W (2006): Social regulation of plasma estradiol concentration in a female anuran. Horm Behav 50:101-106.

Neary TJ, Northcutt RG (1983): Nuclear organization of the bullfrog diencephalon. J Comp Neurol 213:262-278.

Northcutt RG, Kicliter E (1980): Organization of the amphibian telencephalon; in Ebbesson SOE (ed): Comparative Neurology of the Telencephalon. New York, Plenum Press, pp 203-255

-Ormerod BK, Galea LA (2001): Reproductive status influences cell proliferation and cell survival in the dentate gyrus of adult female meadow voles: a possible regulatory role for estradiol. Neuroscience 102:369-379.

Ormerod BK, Galea LA (2003): Reproductive status influences the survival of new cells in the dentate gyrus of adult male meadow voles. Neurosci Lett 346:25-28.

Ormerod BK, Lee TT, Galea LA (2003): Estradiol initially enhances but subsequently suppresses (via adrenal steroids) granule cell proliferation in the dentate gyrus of adult female rats. J Neurobiol 55:247-260.

- Palka YS, Gorbman A (1973): Pituitary and testicular influenced sexual behavior in male frogs, Rana pipiens. Gen Comp Endocrinol 21:148-151

- Pencea V, Bingaman KD, Wiegand SJ, Luskin MB (2001): Infusion of brain-derived neurotrophic factor into the lateral ventricle of the adult rat leads to new neurons in the parenchyma of the striatum, septum, thalamus, and hypothalamus. J Neurosci 21:6706-6717.

Pfaff DW, Schwartz-Giblin S (1988): Cellular mechanisms of female reproductive behaviors; in Knobil E, Neill JD (eds): The Physiology of Reproduction. New York, Raven Press, pp 1487-1568.

- Pierantoni R, Iela L, Delrio G, Rastogi RK (1984): Seasonal plasma sex steroid levels in the female Rana esculenta. Gen Comp Endocrinol 53:126-134.

Polzonetti-Magni AM, Mosconi G, Carnevali O, Yamamoto K, Hanaoka Y, Kikuyama S (1998): Gonadotropins and reproductive function in the anuran amphibian, Rana esculenta. Biol Reprod 58:88-93.

- Rasika S, Nottebohm F, Alvarez-Buylla A (1994): Testosterone increases the recruitment and/ or survival of new high vocal center neurons in adult female canaries. Proc Natl Acad Sci 91:7854-7858. 
Rozenzweig MR, Bennett EL (1977): Experiential influences on brain anatomy and brain chemistry in rodents; in Gottlieb G (ed): Studies on the Development of Behavior and the Nervous System. New York, Academic Press, pp 289-327.

-Salek SJ, Sullivan CV, Godwin J (2001): Courtship behavior of male white perch, Morone americana: evidence for control by androgens. Comp Biochem Physiol 130:731-740.

Sartor JJ, Ball GF (2005): Social suppression of song is associated with a reduction in volume of a song-control nucleus in European starlings (Sturnus vulgaris). Behav Neurosci 119: 233-244.

-Scharfman HE, MacLusky NJ (2006): Estrogen and brain-derived neurotrophic factor (BDNF) in hippocampus: complexity of steroid hormone-growth factor interactions in the adult CNS. Front Neuroendocrinol 27: 415-435.

Schmidt RS (1966): Central mechanisms of frog calling. Behaviour 26:251-285.

-Schmidt RS (1968): Preoptic activation of frog mating behavior. Behaviour 30:239-257.

-Simmons AM, Horowitz SS, Brown RA (2008): Cell proliferation in the forebrain and midbrain of the adult bullfrog, Rana catesbeiana. Brain Behav Evol 71:41-53.

-Sisneros JA, Forlano PM, Deitcher DL, Bass AH (2004): Steroid-dependent auditory plasticity leads to adaptive coupling of sender and receiver. Science New York, NY 305:404407.

- Smith MT, Pencea V, Wang ZX, Luskin MB, Insel TR (2001): Increased number of BrdU-labeled neurons in the rostral migratory stream of the estrous prairie vole. Horm Behav 39:11-21.

-Solis R, Penna M (1997): Testosterone levels and evoked vocal responses in a natural population of the frog Batrachyla taeniata. Horm Behav 31:101-109.
Song CK, Johnstone LM, Schmidt M, Derby CD, Edwards DH (2007): Social domination increases neuronal survival in the brain of juvenile crayfish Procambarus clarkii. J Exp Biol 210:1311-1324.

Spritzer MD, Galea LA (2007): Testosterone and dihydrotestosterone, but not estradiol, enhance survival of new hippocampal neurons in adult male rats. Dev Neurobiol 67:13211333.

Tanapat P, Hastings NB, Reeves AJ, Gould E (1999): Estrogen stimulates a transient increase in the number of new neurons in the dentate gyrus of the adult female rat. J Neurosci 19:5792-5801.

Urano A (1988): Neuroendocrine control of anuran anterior preoptic neurons and initiation of mating behavior. Zool Sci 5:925-937.

- Varriale B, Pierantoni R, Di Matteo L, Minucci S, Fasano S, D’Antonio M, Chieffi G (1986): Plasma and testicular estradiol and plasma androgen profile in the male frog Rana esculenta during the annual cycle. Gen Comp Endocrinol 64:401-404.

Wada M, Gorbman A (1977a): Relation of mode of administration of testosterone to evocation of male sex behavior in frogs. Horm Behav 8:310-319.

Wada M, Gorbman A (1977b): Mate calling induced by electrical-stimulation in freely moving leopard frogs, Rana pipiens. Horm Behav 9:141-149.

Wada M, Wingfield JC, Gorbman A (1976): Correlation between blood level of androgens and sexual behavior in male leopard frogs, Rana pipiens. Gen Comp Endocrinol 29:7277.

Wade J, Crews D (1991): The relationship between reproductive state and 'sexually' dimorphic brain areas in sexually reproducing and parthenogenetic whiptail lizards. J Comp Neurol 309:507-514.

-Wang N, Aviram R, Kirn JR (1999): Deafening alters neuron turnover within the telencephalic motor pathway for song control in adult zebra finches. J Neurosci 19:1055410561.
Weiland NG, Orikasa C, Hayashi S, McEwen BS (1997): Distribution and hormone regulation of estrogen receptor immunoreactive cells in the hippocampus of male and female rats. J Comp Neurol 388:603-612.

-West MJ, Slomianka L, Gundersen HJ (1991): Unbiased stereological estimation of the total number of neurons in the subdivisions of the rat hippocampus using the optical fractionator. Anat Rec 231:482-497.

Wetzel DM, Kelley DB (1983): Androgen and gonadotropin effects on male mate calls in South African clawed frogs, Xenopus laevis. Horm Behav 17:388-404.

Wilczynski W, Allison JD (1989): Acoustic modulation of neural activity in the hypothalamus of the leopard frog. Brain Behav Evol 33: 317-324.

-Wilczynski W, Allison JD, Marler CA (1993): Sensory pathways linking social and environmental cues to endocrine control regions of amphibian forebrains. Brain Behav Evol 42:252-264.

Wilczynski W, Endepols H (2007): Central auditory pathways in anuran amphibians: the anatomical basis of hearing and sound communication; in Narins PM, Feng AS, Fay RR, Popper AN (eds): Hearing and Sound Communication in Amphibians. New York, Springer, pp 221-249.

-Wilczynski W, Lynch KS (2011): Female sexual arousal in amphibians. Horm Behav 59:630636

Wilczynski W, Lynch KS, O’Bryant EL (2005): Current research in amphibians: studies integrating endocrinology, behavior, and neurobiology. Horm Behav 48:440-450.

-Wilczynski W, Ryan MJ (2010): The behavioral neuroscience of anuran social signal processing. Curr Opin Neurobiol 20:754-763. 